\title{
The effects of traffic restriction and family function on paternal perinatal depression during the COVID-19 pandemic in Wuhan, China
}

\author{
Guoqiang Sun ${ }^{1}$ and Yao Cheng ${ }^{1}$ \\ ${ }^{1}$ Affiliation not available
}

April 28, 2020

\begin{abstract}
Objectives The prevention and control of the COVID-19 pandemic might associate with paternal perinatal depression during their partners' delivery. This study aims to investigate the prevalence of paternal perinatal depression exposure to the COVID19 pandemic and to determine the risk factors. Design This is a cross-sectional study Population The participants of perinatal fathers were recruited in one hospital during December 31, 2019 to April 11, 2020 in Wuhan. Methods The Edinburgh Postnatal Depression Scale (EPDS) and the APGAR family function scale was used to evaluate paternal perinatal depression and family function, respectively. The chi-square tests and multivariable logistic regression were applied for data analysis. Results There were 1,187 valid fathers included and the prevalence of paternal perinatal depression was $13.82 \%$. Compared with fathers recruited before the announcement of human-to-human transmission, fathers showed significantly lower risk of perinatal depression ( $\mathrm{OR}=0.54,95 \%$ CI: $0.34,0.87$; $\mathrm{OR}=0.30,95 \% \mathrm{CI}: 0.14,0.63$; respectively) during traffic restriction period and public transportation reopened period in Wuhan. Low or fair of family function significantly associated with elevated risk of paternal perinatal depression $(\mathrm{OR}=2.45,95 \% \mathrm{CI}$ : 1.56, 3.83). Moreover, fathers reported low family income, poor sleep quality, and smoking were significantly associated with increased risks of perinatal depression. Conclusions Paternal screening was suggested to early detect perinatal depression during the COVID-19 pandemic. Traffic restriction and good family function have positive impacts on paternal perinatal depression. These results could provide some evidence for health authorities to formulate targeted prevention and control strategies on paternal perinatal depression.
\end{abstract}

\section{Introduction}

The mental health status of parents plays an important role in the offspring development $(1,2)$. While maternal perinatal depression was well studied, limit studies focused on paternal perinatal depression. Paternal perinatal depression may affect not only the wellbeing of new fathers but their partners and offspring as well. Previous studies demonstrated that paternal perinatal depression was significantly associated with maternal depression (3), and also related with increased risk of physical $(4,5)$, behavioral (6), and emotional problems among the offspring $(7,8)$.

Paternal perinatal depression is becoming an international public health concern. Although the event of becoming a dad is often joyful, fathers should adapt to some potentially stressing reproductive events, including prepare abundant financial support, provide infant care and support to their partners during the reproductive period. Fathers in the transition of parenthood might be prone to paternal perinatal depression.

The Corona Virus Disease 2019 (COVID-19) was first reported in December 2019 in Wuhan, Hubei province and caused a global pandemic. The COVID-19 pandemic poses a great threat to the population's mental health. The Chinese government has promulgated the Guidance Manual on the Prevention and Control of Novel Coronavirus-Infection Pneumonia in the Community issued by the national government (9). Patients 
and accompanies in hospitals are vulnerable to COVID-19 infection. During the COVID-19 pandemic, some fathers have to caring for their partners to delivery in hospital. This might increase the psychological crisis of fathers by the potential risk of infection in hospitals by the dense flow of people, especially for the children and weak partners after delivery.

To reduce human to human transmission, maternal caring hospitals enrolled accompanied fathers based on CT results in the early period of COVID-19 epidemic. After the popularization of nucleic acid detection, hospitals divided the fathers with CT, nucleic acid test, and antibody of COVID-19 in Wuhan. Other public health interventions to control COVID-19 epidemic including traffic restriction globally, which might associate with paternal perinatal depression. Moreover, home quarantine as important method to reduce human-to-human transmission in COVID-19 control, residents stay at home might increase the role of family function.

Currently, there is no document addressed the prevalence and the associated factors of paternal perinatal depression during the COVID-19 epidemic. This study aims to investigate the prevalence of paternal perinatal depression exposure to the COVID-19 pandemic and to determine the risk factors of paternal perinatal depression. This study could provide global prevention and control experience for paternal perinatal depression during the COVID-19 pandemic.

\section{Methods}

\section{Research Design and Data Collection}

This cross-sectional study was conducted to investigate the prevalence of paternal perinatal depression and the associated factors including family function, demographic factor, and health behavior factors. The study was conducted at a maternity care hospital located in Wuhan city. This tertiary hospital is the largest maternal and child care center in Hubei province.

After obtained the approval by the Ethics Committee. Fathers included in this study were recruited following their maternal inpatients with live birth in the hospital (gestational age $>28$ weeks and within 7 days after delivery). Trained doctors and nurses introduced this survey to the eligible fathers and obtained their oral agreement of participation from Dec 31, 2019 to Apr 11, 2020.

\section{Study Instrument}

Perinatal depression was used as a dependent variable and evaluated by the Edinburgh Postnatal Depression Scale (EPDS). The EPDS was compiled by Cox et al. in 1987 and has proved suitable for perinatal depression screening with good reliability and validity (10). The EPDS was also wildly used on fathers in their partners' pregnancy and postpartum $(11,12)$. The EPDS scale contains 10 items, and each item is scored on a fourpoint scale ranging $0-3$ points by severity. In line with previous studies, this study used a total score of $0-9$ points indicating no depression, and 10-30 points indicating depression.

We used 4 periods to address the COVID-19 epidemic as an independent variable in Wuhan, China. Period 1 of pre-epidemic of COVID-19 defined before the official announcement of human to human transmission by the National Health Commission of China (Dec 31, 2019 to Jan 18, 2020); Period 2 of pre-outbreak of COVID-19 with limited number of confirmed patients defined from the announcement of human to human transmission to traffic restrictions (Jan 19, 2020 to Jan 23, 2020); Period 3 of traffic restrictions defined from the outbreak of COVID-19 to the announcement of no increased number of confirmed COVID-19 patients (Jan 24, 2020 to Mar 27, 2020); Period 4 of traffic restrictions dismissed and public traffic transportations reopened (Mar 28, 2020 to Apr 11, 2020). Moreover, we obtained family function as an important independent variable to address the association with paternal perinatal depression. The APGAR scale was used to evaluate family function. The scale was developed by Smilkstein, and includes 5 dimensions of family function (adaptation, partnership, growth, affection, and resolution) (13). Each dimension is divided into 3 levels, with values from 0 (hardly ever) to 2 (almost always). A total score of $0-3$ is considered poor, 4-6 fair, and 7-10 good. 
Demographic factors used as independent variables in this including age $(<29,30-34$, and $>34$ years $)$, ethnicity (Han, other), education (junior high or below, senior high, and college or more), Hukou (rural, urban), family income of last year (<50,000 RMB, 50,000 RMB-100,000 RMB, [?]100,000 RMB, and unclear), insurance (yes, no), and first-time father (yes, no).

Other independent variables of health behavior factors were used in this study, including self-rated sleep quality (good, fair, and poor), smoking/passive smoking within one year (no, yes), drinking/alcohol consumption within one year (no, yes), and exercise within one year (no, yes).

\section{Data analysis}

The chi-square test was used to analyze the differences in paternal perinatal depression and independent variables, including the stages of COVID-19 epidemic, family function, demographic variables (age, ethnicity, education, Hukou, family income, insurance, and first-time father), and health behaviour factors (sleep quality, smoking, drinking, and exercise). Multiple logistic regression analyses were used to evaluate the effects of the independent variables on paternal perinatal depression. Model 1 only included the periods of COVID-19 epidemic and family function. Model 2 included demographic variables on the basis of model 1. Model 3 included health behaviour factors on the bases of model 2. The results of multiple logistic regression analyses are reported as adjusted odds ratios (OR) and $95 \%$ confidence intervals (CI). All tests were two-sided and p-values less than 0.05 were considered statistically significant. Statistical analyses were performed using SAS 9.4 for Windows.

\section{Results}

\section{Prevalence and demographic characteristics}

There were a total of 1,341 eligible fathers participated in this study. After removed 121 of incomplete questionnaires and 33 of self-reported previously confirmed depression patients, 1,187 valid questionnaires (88.52\%) were included in this study. The prevalence of paternal perinatal depression evaluated by the EPDS during the COVID-19 epidemic was $13.82 \%$ in this study (Table 1). Participants aged 30-34 years comprised the highest proportion (44.65\%). Most of the participants were Han nationality (97.56\%), and majority of participants educated with college or more (77.25\%). Participants educated with junior high or below were detected the significantly highest depression rate $(22.22 \%)$. More than half of fathers $(68.13 \%)$ lived in urban city, and $51.90 \%$ of fathers had a family income more than 100,000 RMB. Compared with fathers with family income [?]100,000 RMB, participants with family income $<50,000$ RMB were found higher proportion of perinatal depression $(24.20 \%$ vs $11.36 \%, p=0.0004)$. There was $93.43 \%$ of fathers had insurance and fathers without insurance had higher proportion of perinatal depression $(28.21 \%$ vs $12.80 \%, p$ $=0.0001)$. Almost two-thirds of participants $(67.31 \%)$ were first-time fathers and they have significantly lower proportion of perinatal depression compared with others $(11.83 \%$ vs $18.41 \%, p=0.0034)$.

\section{Health behavior characteristics}

Among the participants, $75.24 \%$ reported to have good sleep quality during the last year. Compared with fathers reported poor sleep quality, fathers with good sleep quality has significantly lower proportion of perinatal depression $(8.94 \%$ vs $35.00 \%, p<0.0001)$ (Table 2). Less than half of participants $(41.16 \%)$ reported smoking during the past year, and they were detected with a higher proportion of perinatal depression compared with those who didn't smoking $(18.45 \%$ vs $10.70 \%, p=0.0002)$. There were $56.42 \%$ of participants had alcohol consumption and $64.94 \%$ of participants had exercise in the last year.

\section{Independent variables}

Prevalence of paternal perinatal depression was significant different during the 4 periods of COVID-19 pandemic (Table 3). From the official published unknown pneumonia in December, 2019 to the announcement of human to human transmission of COVID-19, the prevalence of paternal perinatal depression was significantly higher than other 3 periods $(p=0.001)$. Moreover, majority of fathers $(86.18 \%)$ reported good family 
function, and they had lower depression compared with those reported fair of family function $(11.53 \%$ vs $32.31 \%, p<0.0001)$.

\section{Predictors of paternal prenatal depression}

Compared with fathers recruited before the announcement of human-to-human transmission, fathers reported significantly lower risk of perinatal depression during traffic restrictions and traffic restrictions dismissed periods $(\mathrm{OR}=0.54,95 \%$ CI: $0.34,0.87$; $\mathrm{OR}=0.30,95 \%$ CI: $0.14,0.63$; respectively) (Table 4). Family function was a statistically significant risk factor for paternal perinatal depression. Low or fair of family function significantly associated with elevated risk of paternal perinatal depression ( $\mathrm{OR}=2.45,95 \%$ CI: 1.56 , 3.83). For demographic factors, fathers with low family income $(<50,000 \mathrm{RMB})$ was significantly associated with increased risk of perinatal depression ( $\mathrm{OR}=1.75,95 \%$ CI: 1.36, 4.44). For health behavior factors, poor/fair of sleep quality related with increased risk of perinatal depression ( $\mathrm{OR}=3.18,95 \%$ CI: 2.19, 4.63). Fathers had smoking habitat were found increased risk of perinatal depression ( $\mathrm{OR}=1.50,95 \%$ CI: 1.03 , $2.20)$.

\section{Discussion}

Main findings The prevalence of paternal perinatal depression $13.82 \%$ in Wuhan, China. Traffic restriction in the COVID-19 public health containment and family function were significantly associated with paternal perinatal depression.

\section{Strengths and limitations}

This is a unique study reported the prevalence of paternal perinatal depression during the COVID-19 pandemic in Wuhan, China. And the result novelty reveled that traffic restriction in Wuhan was associated with decreased risk of paternal perinatal depression.

This study has several limitations. First, this cross-sectional design couldn't reveal the causal relationships among factors. Second, this study was self-reported, thus the measurement accuracy of paternal depression and other related fathers was compromised. Third, the findings of this study targeted on fathers in hospitals and cannot be generalized to fathers during the entire perinatal period. Moreover, this study draw conclusion based on one hospital in Wuhan, multi-center studies was necessary to further address the risk factors of paternal depression.

The prevalence of paternal perinatal depression in Wuhan was higher than the global level of 5-10\% (14, 15). Firstly, this variation of paternal perinatal depression prevalence might be explained by the different depression tool. On the other hand, fathers in different perinatal period and in different geographical distribution might also have contributed to the unequal prevalence of paternal perinatal depression. Moreover, the COVID-19 epidemic might have partly resulted in the high prevalence of paternal perinatal depression in Wuhan.

Critically, our study revealed that the prevalence of paternal perinatal depression before the announcement of human to human transmission comprised the highest proportion during the COVID-19 epidemic, and traffic restriction associated with relatively decreased risk of paternal perinatal depression in Wuhan. The elevated risk of paternal perinatal depression before the announcement of human to human transmission might be partly due to the concern of the obscure and uncertainty of COVID-19 epidemic. Traffic restriction as effective measures of COVID control, it might help to lower the paternal depression by gain more confidence on maternal and child protection from COVID-19 infection. This result possibly indicated that effective control measures adopted by officials might have positive effect to alleviate paternal depression.

Previous studies have found that family dysfunction is an important contributor to a wild range of depression among adolescents (16), students (17), caregivers and patients (18), and the elders (19). Women's satisfaction from the family function was proved to be a significant factor protect against the occurrence of mental health disturbances (20). It was demonstrated that paternal depression was associated with an increased risk of family dysfunction of disharmony in partner relationships (21). This study further supported the point 
that fathers reported poor or fair of family function have a negative effect on the prevalence of perinatal depression during the COVID-19 epidemic. Further longitudinal studies are necessary to investigate the causal relationship on the effect of family function on paternal perinatal depression.

As another predictive factor of paternal depression, fathers reported low household incomes have a higher risk of paternal depression, which was in line with previous studies $(22,23)$. The coming of new baby might aggregate the financial pressure on fathers. However, this study demonstrated a relative low percent of fathers reported poor family income. This factor is dynamic and the income of maternal partners during pregnancy is often lower than the average level. With the improving in family income, the negative effect on paternal perinatal depression might considerably reduce.

E Juulia Paavonen et al reported that sleep disorders associated with 1.9 times of elevated risk of male depression during pregnancy (24). Deborah Da Costa et al demonstrated poor sleep quality was associated with postpartum depressive symptoms among first-time fathers (25). This study was further confirmed that sleep was a strong predictor of paternal depression in Wuhan. Paternal sleep quality might be compromised by pregnant partners' irregular sleep behavior and extra caring for maternal health.

The relationship of maternal depression and smoking prepregnancy and prenatally was firmly established previously (26-28). This study interestingly showed that fathers have smoking or passive smoking behavior showed an elevated risk of perinatal depression. This relationship could be partly explained that the intake of nicotine by smoking or passive smoking has neurobiologic impact on the brain which related with depression (29).

\section{Implications for public health practice}

The prevalence of paternal perinatal depression was relatively high, which provided strong support for paternal screening to early detect depression symptoms among perinatal fathers during the COVID-19 epidemic. With the wildly adopted measure of traffic restriction on COVID-19 control, improve the family function of fathers might be helpful in perinatal depression management.

\section{Conclusions}

This study revealed that traffic restrictions didn't associated with paternal perinatal depression and family function have positive impact on paternal perinatal depression, these results could provide some evidence for health authorities to formulate targeted prevention and control strategies on paternal perinatal depression during the COVID-19 epidemic. In summary, this study identified potential risk factors of paternal perinatal depression during the COVID-19 epidemic, which provides foundation for prospective studies to further address the associations.

\section{Contribution to authorship}

YC contributed to the design, carrying out, data analysing, and wrote the manuscript. GS conducted the design, interpretation of the data, and reviewed the manuscript. All authors approved the final draft.

\section{Details of ethics approval}

This study was approved by the Ethics Committee of Maternal and Child Care Hospital of Hubei Province [2020] IEC (A007) on Dec 8, 2019.

\section{Funding}

None

\section{Acknowledgements}

None

\section{References}


1. Sweeney S, MacBeth A. The effects of paternal depression on child and adolescent outcomes: A systematic review. J Affect Disord. 2016 Nov 15;205:44-59. PubMed PMID: 27414953.

2. Korja R, Nolvi S, Kataja EL, Scheinin N, Junttila N, Lahtinen H, et al. The courses of maternal and paternal depressive and anxiety symptoms during the prenatal period in the FinnBrain Birth Cohort study. PLoS One. 2018;13(12):e0207856. PubMed PMID: 30557345. Pubmed Central PMCID: 6296666.

3. Sundstrom Poromaa I, Comasco E, Georgakis MK, Skalkidou A. Sex differences in depression during pregnancy and the postpartum period. Journal of neuroscience research. 2017 Jan 2;95(1-2):719-30. PubMed PMID: 27870443. Pubmed Central PMCID: 5129485.

4. Liu C, Cnattingius S, Bergstrom M, Ostberg V, Hjern A. Prenatal parental depression and preterm birth: a national cohort study. BJOG : an international journal of obstetrics and gynaecology. 2016 Nov;123(12):1973-82. PubMed PMID: 26786413. Pubmed Central PMCID: 5096244.

5. Takehara K, Suto M, Kakee N, Tachibana Y, Mori R. Prenatal and early postnatal depression and child maltreatment among Japanese fathers. Child abuse \& neglect. 2017 Aug;70:231-9. PubMed PMID: 28633058 .

6. Cui C, Li M, Yang Y, Liu C, Cao P, Wang L. The effects of paternal perinatal depression on socioemotional and behavioral development of children: A meta-analysis of prospective studies. Psychiatry research. 2020 Feb;284:112775. PubMed PMID: 31927302.

7. Gutierrez-Galve L, Stein A, Hanington L, Heron J, Ramchandani P. Paternal depression in the postnatal period and child development: mediators and moderators. Pediatrics. 2015 Feb;135(2):e339-47. PubMed PMID: 25560437.

8. Tichovolsky MH, Griffith SF, Rolon-Arroyo B, Arnold DH, Harvey EA. A Longitudinal Study of Fathers' and Young Children's Depressive Symptoms. Journal of clinical child and adolescent psychology : the official journal for the Society of Clinical Child and Adolescent Psychology, American Psychological Association, Division 53. 2018;47(sup1):S190-S204. PubMed PMID: 27654698. Pubmed Central PMCID: 6098980.

9. National Health Commission of the People's Republic of China. Notice on Issuing novel coronavirus infection pneumonia emergency psychological crisis intervention guidelines. March 1, 2020 (in Chinese). http://wwwnhcgovcn/jkj/s3577/202001/6adc08b966594253b2b791be5c3b9467shtml. (Accessed March 1, 2020).

10. Cox JL, Holden JM, Sagovsky R. Detection of postnatal depression. Development of the 10-item Edinburgh Postnatal Depression Scale. Br J Psychiatry. 1987 Jun;150:782-6. PubMed PMID: 3651732. Epub 1987/06/01.

11. Ierardi E, Ferro V, Trovato A, Tambelli R, Riva Crugnola C. Maternal and paternal depression and anxiety: their relationship with mother-infant interactions at 3 months. Archives of women's mental health. 2019 Aug;22(4):527-33. PubMed PMID: 30341645. Epub 2018/10/21.

12. Top ED, Cetisli NE, Guclu S, Zengin EB. Paternal Depression Rates in Prenatal and Postpartum Periods and Affecting Factors. Archives of psychiatric nursing. 2016 Dec;30(6):747-52. PubMed PMID: 27888970. Epub 2016/11/28.

13. Smilkstein G. The family APGAR: a proposal for a family function test and its use by physicians. J Fam Pract. 1978 Jun;6(6):1231-9. PubMed PMID: 660126. Epub 1978/06/01.

14. Darwin Z, Galdas P, Hinchliff S, Littlewood E, McMillan D, McGowan L, et al. Fathers' views and experiences of their own mental health during pregnancy and the first postnatal year: a qualitative interview study of men participating in the UK Born and Bred in Yorkshire (BaBY) cohort. BMC Pregnancy Childbirth. 2017 Jan 26;17(1):45. PubMed PMID: 28125983. Pubmed Central PMCID: PMC5270346. Epub $2017 / 01 / 28$. 
15. Gray PB, Reece JA, Coore-Desai C, Dinnall-Johnson T, Pellington S, Bateman A, et al. Patterns and predictors of depressive symptoms among Jamaican fathers of newborns. Social psychiatry and psychiatric epidemiology. 2018 Oct;53(10):1063-70. PubMed PMID: 30062481. Epub 2018/08/01.

16. Lin HC, Tang TC, Yen JY, Ko CH, Huang CF, Liu SC, et al. Depression and its association with selfesteem, family, peer and school factors in a population of 9586 adolescents in southern Taiwan. Psychiatry and clinical neurosciences. 2008 Aug;62(4):412-20. PubMed PMID: 18778438. Epub 2008/09/10.

17. Zhao S, Yiyue G. The effects of mother's education on college student's depression level: The role of family function. Psychiatry research. 2018 Nov;269:108-14. PubMed PMID: 30145289. Epub 2018/08/27.

18. Han SH, Kim B, Lee SA. Contribution of the family environment to depression in Korean adults with epilepsy. Seizure. 2015 Feb;25:26-31. PubMed PMID: 25645631. Epub 2015/02/04.

19. Zou C, Chen S, Shen J, Zheng X, Wang L, Guan L, et al. Prevalence and associated factors of depressive symptoms among elderly inpatients of a Chinese tertiary hospital. Clinical interventions in aging. 2018;13:1755-62. PubMed PMID: 30271130. Pubmed Central PMCID: PMC6145362. Epub 2018/10/03.

20. Sprusińska E. The Family APGAR Index: study on relationship between family function, social support, global stress and mental health perception in women. International journal of occupational medicine and environmental health. 1994;7(1):23-32. PubMed PMID: 7921899. Epub 1994/01/01.

21. Ramchandani PG, Psychogiou L, Vlachos H, Iles J, Sethna V, Netsi E, et al. Paternal depression: an examination of its links with father, child and family functioning in the postnatal period. Depression and anxiety. 2011 Jun;28(6):471-7. PubMed PMID: 21506206. Pubmed Central PMCID: PMC3128925. Epub $2011 / 04 / 21$.

22. Dismuke CE, Egede LE. Association between major depression, depressive symptoms and personal income in US adults with diabetes. General hospital psychiatry. 2010 Sep-Oct;32(5):484-91. PubMed PMID: 20851268. Epub 2010/09/21.

23. Gerogianni G, Lianos E, Kouzoupis A, Polikandrioti M, Grapsa E. The role of socio-demographic factors in depression and anxiety of patients on hemodialysis: an observational cross-sectional study. International urology and nephrology. 2018 Jan;50(1):143-54. PubMed PMID: 29159509. Epub 2017/11/22.

24. Juulia Paavonen E, Saarenpää-Heikkilä O, Pölkki P, Kylliäinen A, Porkka-Heiskanen T, Paunio T. Maternal and paternal sleep during pregnancy in the Child-sleep birth cohort. Sleep medicine. 2017 Jan;29:4756. PubMed PMID: 28153216. Epub 2017/02/06.

25. Da Costa D, Danieli C, Abrahamowicz M, Dasgupta K, Sewitch M, Lowensteyn I, et al. A prospective study of postnatal depressive symptoms and associated risk factors in first-time fathers. J Affect Disord. 2019 Apr 15;249:371-7. PubMed PMID: 30818245. Epub 2019/03/01.

26. Smedberg J, Lupattelli A, Mårdby AC, Øverland S, Nordeng H. The relationship between maternal depression and smoking cessation during pregnancy-a cross-sectional study of pregnant women from 15 European countries. Archives of women's mental health. 2015 Feb;18(1):73-84. PubMed PMID: 25352316. Epub 2014/10/30.

27. De Wilde KS, Trommelmans LC, Laevens HH, Maes LR, Temmerman M, Boudrez HL. Smoking patterns, depression, and sociodemographic variables among Flemish women during pregnancy and the postpartum period. Nursing research. 2013 Nov-Dec;62(6):394-404. PubMed PMID: 24165215. Epub 2013/10/30.

28. Tong VT, Farr SL, Bombard J, D'Angelo D, Ko JY, England LJ. Smoking Before and During Pregnancy Among Women Reporting Depression or Anxiety. Obstetrics and gynecology. 2016 Sep;128(3):562-70. PubMed PMID: 27500342. Pubmed Central PMCID: PMC5013536. Epub 2016/08/09.

29. Tojal C, Costa R. Anxiety and depression symptoms among pregnant women with different smoking habits. Psychology, health \& medicine. 2019 Jun 24:1-8. PubMed PMID: 31232092. Epub 2019/06/25. 
Table 1. Descriptive statistics for the demographic factors of participants during the COVID19 epidemic.

\begin{tabular}{|c|c|c|c|c|c|}
\hline Variables & $\begin{array}{l}\text { No depression } \\
\text { N (\%) }\end{array}$ & $\begin{array}{l}\text { Depression } \mathrm{N} \\
(\%)\end{array}$ & Total N (\%) & $\chi^{2}$ & $P$ \\
\hline Age & & & & 7.1152 & 0.0285 \\
\hline$<29$ & $309(89.57)$ & $36(10.43)$ & $345(29.06)$ & & \\
\hline $30-34$ & $457(86.23)$ & $73(13.77)$ & $530(44.65)$ & & \\
\hline$>34$ & $257(82.37)$ & $55(17.63)$ & $312(26.28)$ & & \\
\hline Total & $1023(86.18)$ & $164(13.82)$ & $1187(100.00)$ & & \\
\hline Ethnicity & & & & 2.6813 & 0.1015 \\
\hline Han & $995(85.92)$ & $163(14.08)$ & $1158(97.56)$ & & \\
\hline Other & $28(96.55)$ & $1(3.45)$ & $29(2.44)$ & & \\
\hline Education & & & & 8.6248 & 0.0134 \\
\hline $\begin{array}{l}\text { Junior high or } \\
\text { below }\end{array}$ & $63(77.78)$ & $18(22.22)$ & $81(6.82)$ & & \\
\hline Senior high & $156(82.54)$ & $33(17.46)$ & $189(15.92)$ & & \\
\hline $\begin{array}{l}\text { College or } \\
\text { more }\end{array}$ & $804(87.68)$ & $113(12.32)$ & $917(77.25)$ & & \\
\hline Hukou & & & & 3.3049 & 0.0691 \\
\hline Rural & $316(83.60)$ & $62(16.40)$ & $378(31.87)$ & & \\
\hline Urban & $707(87.50)$ & $101(12.50)$ & $808(68.13)$ & & \\
\hline $\begin{array}{l}\text { Family income } \\
(\mathrm{RMB})\end{array}$ & & & & 18.2919 & 0.0004 \\
\hline$<50,000$ & $119(75.80)$ & $38(24.20)$ & $157(13.23)$ & & \\
\hline $50,000-100,000$ & $259(85.48)$ & $44(14.52)$ & $303(25.53)$ & & \\
\hline [?]100,000 & $546(88.64)$ & $70(11.36)$ & $616(51.90)$ & & \\
\hline Unclear & $99(89.19)$ & $12(10.81)$ & $111(9.35)$ & & \\
\hline Insurance & & & & 14.5037 & 0.0001 \\
\hline Yes & $967(87.20)$ & $142(12.80)$ & $1109(93.43)$ & & \\
\hline No & $56(71.79)$ & $22(28.21)$ & $78(6.57)$ & & \\
\hline $\begin{array}{l}\text { First-time } \\
\text { father }\end{array}$ & & & & 8.5573 & 0.0034 \\
\hline Yes & $641(88.17)$ & $86(11.83)$ & $727(67.31)$ & & \\
\hline No & $288(81.59)$ & $65(18.41)$ & $353(32.69)$ & & \\
\hline
\end{tabular}

No depression: EPDS score 0-9; Depression: EPDS score 10-30.

Table 2. Descriptive statistics for the health behavior factors of participants during the COVID-19 epidemic.

\begin{tabular}{llllll}
\hline Variables & $\begin{array}{l}\text { No depression } \\
\text { N (\%) }\end{array}$ & $\begin{array}{l}\text { Depression } \mathbf{N} \\
\mathbf{( \% )}\end{array}$ & Total N (\%) & $\chi^{2}$ & $P$ \\
\hline Sleep quality & & & & 72.6286 & $<0.0001$ \\
Good & $794(91.06)$ & $78(8.94)$ & $872(75.24)$ & & \\
Fair & $191(71.54)$ & $76(28.46)$ & $267(23.04)$ & & \\
Poor & $13(65.00)$ & $7(35.00)$ & $20(1.73)$ & & \\
Smoking & & & & & \\
No & $609(89.30)$ & $73(10.70)$ & $682(58.84)$ & & \\
Yes & $389(81.55)$ & $88(18.45)$ & $477(41.16)$ &
\end{tabular}




\begin{tabular}{llllll}
\hline Variables & $\begin{array}{l}\text { No depression } \\
\text { N (\%) }\end{array}$ & $\begin{array}{l}\text { Depression } \mathbf{N} \\
\mathbf{( \% )}\end{array}$ & Total N (\%) & $\chi^{2}$ & $P$ \\
\hline $\begin{array}{l}\text { Drinking } \\
\text { No }\end{array}$ & $441(87.15)$ & $65(12.85)$ & $506(43.58)$ & 0.7829 & 0.3763 \\
Yes & $559(85.34)$ & $96(14.66)$ & $655(56.42)$ & & \\
Exercise & & & & \\
No & $341(83.99)$ & $65(16.01)$ & $406(35.06)$ & & 0.1122 \\
Yes & $657(87.37)$ & $95(12.63)$ & $752(64.94)$ & & \\
\hline
\end{tabular}

No depression: EPDS score 0-9; Depression: EPDS score 10-30.

Table 3. Descriptive statistics for independent variables of participants during the COVID-19 epidemic.

\begin{tabular}{llllll}
\hline Variables & $\begin{array}{l}\text { No depression } \\
\text { N (\%) }\end{array}$ & $\begin{array}{l}\text { Depression } \mathbf{N} \\
\mathbf{( \% )}\end{array}$ & Total N (\%) & $\chi^{2}$ & $P$ \\
\hline $\begin{array}{l}\text { Period of } \\
\text { COVID-19 }\end{array}$ & $\begin{array}{l}\text { Period of } \\
\text { COVID-19 }\end{array}$ & & & 16.2496 & 0.001 \\
epidemic & $\begin{array}{l}\text { epidemic } \\
\text { Period 1 }\end{array}$ & $143(78.14)$ & $40(21.86)$ & $183(15.42)$ & \\
Period 2 & $80(85.11)$ & $14(14.89)$ & $94(7.92)$ & \\
Period 3 & $638(86.80)$ & $97(13.20)$ & $735(61.92)$ & & \\
Period 4 & $162(92.57)$ & $13(7.43)$ & $175(14.74)$ & 41.8878 & \\
Family & & & & \\
function & $30(88.24)$ & $4(11.76)$ & $34(2.86)$ & \\
Poor & $88(67.69)$ & $42(32.31)$ & $130(10.95)$ & & \\
Fair & $905(88.47)$ & $118(11.53)$ & $1023(86.18)$ & & \\
Good & & & & \\
\hline
\end{tabular}

No depression: EPDS score 0-9; Depression: EPDS score 10-30.

Period 1: before the announcement of human to human transmission (Dec 31, 2019 to Jan 18, 2020); Period 2: From the announcement of human to human transmission to traffic restrictions (Jan 19, 2020 to Jan 23, 2020); Period 3: Traffic restrictions (Jan 24, 2020 to Mar 27, 2020); Period 4: Traffic restrictions dismissed (Mar 28, 2020 to Apr 11, 2020).

Table 4. Logistic regression analysis for the effects of independent variables on paternal depression .

\begin{tabular}{llll}
\hline Variables & Crude OR $(\mathbf{9 5 \%} \mathbf{C I})$ & $\begin{array}{l}\text { Adjusted OR } \mathbf{( 9 5 \%} \\
\mathbf{C I})\end{array}$ & $\begin{array}{l}\text { Adjusted OR } \mathbf{9 5 \%} \\
\mathbf{C I})\end{array}$ \\
\hline $\begin{array}{l}\text { Period of COVID-19 } \\
\text { epidemic (in reference }\end{array}$ & $\begin{array}{l}\text { Period of COVID-19 } \\
\text { epidemic (in reference }\end{array}$ & $\begin{array}{l}\text { Period of COVID-19 } \\
\text { epidemic (in reference }\end{array}$ & $\begin{array}{l}\text { Period of COVID-19 } \\
\text { epidemic (in reference }\end{array}$ \\
to Period 1) & to Period 1) & $0.65(0.32,1.32)$ & to Period 1) \\
Period 2 & $0.68(0.34,1.34)$ & $0.54(0.34,0.85)^{* *}$ & $0.54(0.28,1.21)$ \\
$\begin{array}{l}\text { Period 3 } \\
\text { Period 4 }\end{array}$ & $0.60(0.39,0.94)^{*}$ & $0.29(0.14,0.59)^{* * *}$ & $0.30(0.14,0.63)^{* *}$ \\
Family function & $0.32(0.16,0.63)^{* *}$ & & \\
Poor/fair vs Good & $3.20(2.12,4.83)^{* * *}$ & $3.02(1.97,4.63)^{* * *}$ & $2.45(1.56,3.83)^{* * *}$
\end{tabular}




\begin{tabular}{|c|c|c|c|}
\hline Variables & Crude OR $(95 \% \mathrm{CI})$ & $\begin{array}{l}\text { Adjusted OR (95\% } \\
\text { CI) }\end{array}$ & $\begin{array}{l}\text { Adjusted OR (95\% } \\
\text { CI) }\end{array}$ \\
\hline $\begin{array}{l}\text { Age (in reference to } \\
<29 \text { years) }\end{array}$ & $\begin{array}{l}\text { Age (in reference to } \\
<29 \text { years) }\end{array}$ & & \\
\hline $30-34$ & & $1.41(0.89,2.23)$ & $1.30(0.81,2.09)$ \\
\hline$>34$ & & $1.78(1.06,3.00)^{*}$ & $1.52(0.89,2.59)$ \\
\hline $\begin{array}{l}\text { Education (in reference } \\
\text { to Junior high or } \\
\text { below) }\end{array}$ & $\begin{array}{l}\text { Education (in reference } \\
\text { to Junior high or } \\
\text { below) }\end{array}$ & $\begin{array}{l}\text { Education (in reference } \\
\text { to Junior high or } \\
\text { below) }\end{array}$ & \\
\hline Senior high & & $0.90(0.45,1.82)$ & $1.06(0.51,2.8)$ \\
\hline College or more & & $0.80(0.41,1.57)$ & $1.07(0.53,2.13)$ \\
\hline \multicolumn{4}{|l|}{ Hukou } \\
\hline Urban vs Rural & & $0.87(0.58,1.32)$ & $0.86(0.56,1.31)$ \\
\hline $\begin{array}{l}\text { Family income (in } \\
\text { reference to [?]100,000 } \\
\text { RMB) }\end{array}$ & $\begin{array}{l}\text { Family income (in } \\
\text { reference to [?]100,000 } \\
\text { RMB) }\end{array}$ & & \\
\hline $50,000-100,000$ & & $1.17(0.75,1.83)$ & $1.06(0.67,1.68)$ \\
\hline$<50,000$ & & $2.02(1.21,3.36)^{* *}$ & $1.75(1.03,2.96)^{*}$ \\
\hline \multicolumn{4}{|l|}{ Insurance } \\
\hline No vs Yes & & $2.22(1.25,3.94)^{* *}$ & $2.46(1.36,4.44)^{* *}$ \\
\hline \multicolumn{4}{|l|}{ First-time father } \\
\hline No vs Yes & & $1.36(0.90,2.04)$ & $1.30(0.85,1.97)$ \\
\hline Sleep quality & Sleep quality & & \\
\hline $\begin{array}{l}\text { Poor/fair vs Good } \\
\text { Smoking }\end{array}$ & & & $3.18(2.19,4.63)^{* * *}$ \\
\hline Yes vs No & & & $1.50(1.03,2.20)^{*}$ \\
\hline \multicolumn{4}{|l|}{ Drinking } \\
\hline Yes vs No & & & $1.05(0.71,1.53)$ \\
\hline \multicolumn{4}{|l|}{ Exercise } \\
\hline Yes vs No & & & $0.92(0.63,1.34)$ \\
\hline
\end{tabular}

Period 1: before the announcement of human to human transmission (Dec 31, 2019 to Jan 18, 2020); Period 2: From the announcement of human to human transmission to traffic restrictions (Jan 19, 2020 to Jan 23, 2020); Period 3: Traffic restrictions (Jan 24, 2020 to Mar 27, 2020); Period 4: Traffic restrictions dismissed (Mar 28, 2020 to Apr 11, 2020).

${ }^{* * *} \mathrm{p}<0.001,{ }^{* *} \mathrm{p}<0.01,{ }^{*} \mathrm{p}<0.05$ 